\title{
Correction: Oubennaceur, K., et al. Uncertainty Analysis of a Two-Dimensional Hydraulic Model. Water 2018, 10, 272
}

\author{
Khalid Oubennaceur ${ }^{1, *} \mathbb{C}^{\mathbb{D}}$, Karem Chokmani ${ }^{1}$, Miroslav Nastev ${ }^{2}$, Marion Tanguy ${ }^{1}$ and \\ Sebastien Raymond ${ }^{1}$ \\ 1 Centre Eau Terre Environnement, INRS, 490 De la Couronne Street, Quebec, QC G1K 9A9, Canada; \\ karem.chokmani@ete.inrs.ca (K.C.); marion.tanguy@ete.inrs.ca (M.T.); sebastien.raymond@ete.inrs.ca (S.R.) \\ 2 Geological Survey of Canada, 490 De la Couronne Street, 3rd Floor, Quebec, QC G1K 9A9, Canada; \\ miroslav.nastev@canada.ca \\ * Correspondence: Khalid.Oubennaceur@ete.inrs.ca; Tel.: +1-418-999-0861
}

Received: 27 July 2018; Accepted: 30 July 2018; Published: 10 August 2018

The authors wish to make the following corrections to this paper [1]:

(1) In Section 2.2, hydraulic Model of the Richelieu River, Line 5 of the first paragraph, reference 67 should be added at the end as follows: " ... the two equations of momentum conservation (3) and (4) under steady-state flow conditions with special treatment of drying-wetting areas [67]."

(2) After a minor correction of editorial typos, Equations (2)-(4) should be the following:

$$
\begin{gathered}
\frac{\partial h}{\partial t}+\frac{\partial q_{x}}{\partial x}+\frac{\partial q_{y}}{\partial y}+(\gamma+\delta)\left(\frac{\partial^{2} h}{\partial x^{2}}+\frac{\partial^{2} h}{\partial y^{2}}\right)=0 \\
\frac{\partial q_{x}}{\partial t}+\frac{\partial}{\partial x}\left(\frac{q_{x} q_{x}}{H}\right)+\frac{\partial}{\partial y}\left(\frac{q_{x} q_{y}}{H}\right)+c^{2} \frac{\partial h}{\partial x}-\frac{1}{\rho} \times\left[\frac{\partial}{\partial x}\left(H \tau_{x x}\right)+\frac{\partial}{\partial y}\left(H \tau_{x y}\right)-\tau_{x}^{b}+\tau_{x}^{s}\right]-f_{c} q_{y}=0 \\
\frac{\partial q_{y}}{\partial t}+\frac{\partial}{\partial x}\left(\frac{q_{y} q_{x}}{H}\right)+\frac{\partial}{\partial y}\left(\frac{q_{y} q_{y}}{H}\right)+c^{2} \frac{\partial h}{\partial y}-\frac{1}{\rho} \times\left[\frac{\partial}{\partial x}\left(H \tau_{y x}\right)+\frac{\partial}{\partial y}\left(H \tau_{y y}\right)-\tau_{y}^{b}+\tau_{y}^{s}\right]+f_{c} q_{x}=0
\end{gathered}
$$

(3) Six editorial corrections were made in the paragraph of the Equations (2)-(4) (Page 6/19, 1st paragraph, lines 1 to 7 ):

- The flow rate $\mathrm{m}^{2} / \mathrm{s}$.

- $\quad$ The sentence " $r$ is the water density" should be deleted.

- $\quad$ The sentence " $\gamma$ Lapidus coefficient" should be added.

- The sentence " $\delta$ hydraulic conductivity (set to 0 in wet areas and to 1 in dry areas)" should be added.

- The sentence "The model does not take into account the influence of the wind and the Coriolis force" should be deleted.

- The sentence "The continuous fields $\mathrm{h}, \mathrm{u}$ and $\mathrm{v}$ are discretized over structured mesh" should mention an unstructured mesh instead of a structured one.

Therefore, the paragraph should read:

"where $\mathrm{q}_{\mathrm{x}}$ and $\mathrm{q}_{\mathrm{y}}$ are the flow rates in $\mathrm{x}$ and y direction $\left(\mathrm{m}^{2} / \mathrm{s}\right), \mathrm{h}$ is the water level $(\mathrm{m}), \mathrm{H}$ is the depth of water, $\mathrm{c}$ is wave velocity $(\mathrm{m} / \mathrm{s}), \rho$ is the density, $\mathrm{u}(\mathrm{u}, \mathrm{v})$ are the components of the of velocity vector $(\mathrm{m} / \mathrm{s}), \gamma$ Lapidus coefficient, $\delta$ hydraulic 
conductivity (set to 0 in wet areas and to 1 in dry areas), $\mathrm{f}_{\mathrm{c}}$ is the Coriolis force, $\tau_{\mathrm{ij}}$ is the Reynolds stresses $\left(\mathrm{m} / \mathrm{s}^{2} \mathrm{~m}\right), \tau_{\mathrm{x}}^{\mathrm{b}}$ and $\tau_{\mathrm{y}}^{\mathrm{b}}$ are the bottom frictions in the $\mathrm{x}$ and $\mathrm{y}$ directions $\left(\mathrm{kg} / \mathrm{s}^{2} \mathrm{~m}\right), \tau_{\mathrm{x}}^{\mathrm{s}}$ and $\tau_{\mathrm{y}}^{\mathrm{s}}$ are the surface frictions in the $\mathrm{x}$ and $\mathrm{y}$ directions $\left(\mathrm{kg} / \mathrm{s}^{2} \mathrm{~m}\right)$, and $x(x, y)$ are the components of coordinate orientation of $X(m)$. The continuous fields $h, u$ and $\mathrm{v}$ are discretized over unstructured mesh of finite element triangles of six nodes, referred to as T6L."

(4) In line 4 of the last paragraph Page $6 / 19$, the model domain used an unstructured mesh and not a structured one. Thus, the corresponding sentence should read:

“... The model domain was discretized over a unstructured mesh of 47,643 finite elements and 97,261 nodes, ..."

(5) In Section 2.2, reference 70 should be deleted.

The authors would like to apologize for any inconvenience caused to the readers by these changes. The changes do not affect the scientific results. The manuscript will be updated and the original will remain online on the article webpage, with a reference to this correction.

\section{Reference}

1. Oubennaceur, K.; Chokmani, K.; Nastev, M.; Tanguy, M.; Raymond, S. Uncertainty Analysis of a Two-Dimensional Hydraulic Model. Water 2018, 10, 272. [CrossRef] 